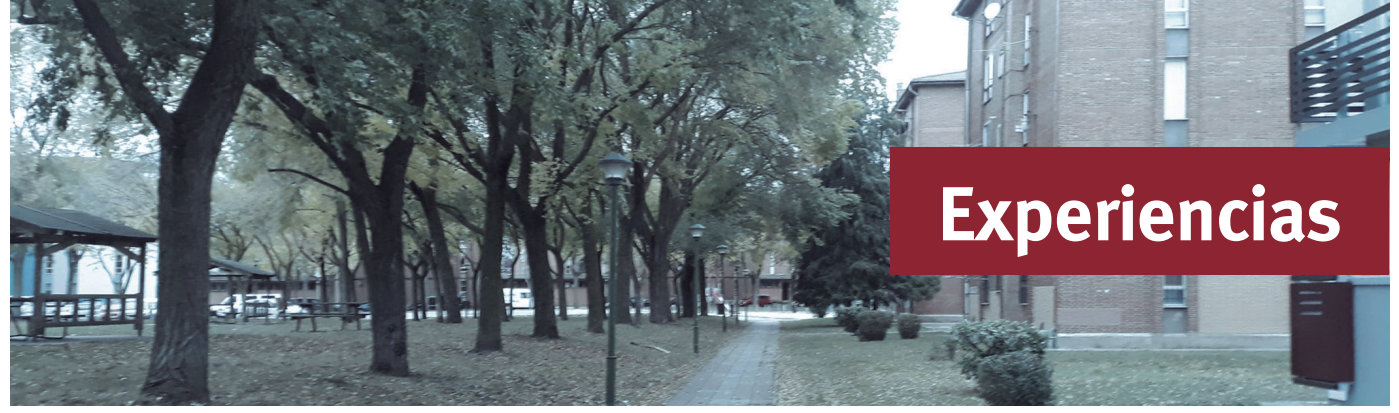

CIUDAD Y TERRITORIO

ESTUDIOS TERRITORIALES

ISSN(P): 1133-4762; ISSN(E): 2659-3254

Vol. LII, № 203, primavera 2020

Págs. 151-158

https://doi.org/10.37230/CyTET.2020.203.12

CC BY-NC 4.0

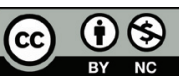

\title{
Área de Regeneración Urbana del Barrio San Cristóbal de Burgos ${ }^{1}$
}

\author{
Rafael Córdoba-Hernández (1) \\ Fernando CARMona-MATEOS ${ }^{(2)}$ \\ Emilia ROMÁN-LóPEZ ${ }^{(3)}$ \\ Carmen Sánchez-Guevara ${ }^{(4)}$
}

\begin{abstract}
(1) Miembro de ONU-Habitat Planners for Climate Action ( $\mathrm{P}_{4} \mathrm{CA}$ ), Profesor asociado del Departamento de Urbanística y Ordenación del Territorio de la Escuela Técnica Superior de Arquitectura de la Universidad Politécnica de Madrid ${ }^{(2)}$ Arquitecto e investigador del Instituto Juan de Herrera de la Escuela Técnica Superior de Arquitectura de la Universidad Politécnica de Madrid (3)Profesora ayudante doctora del Departamento de Urbanística y Ordenación del Territorio de la Escuela Técnica Superior de Arquitectura de la Universidad Politécnica de Madrid (4) Profesora ayudante doctora del Departamento de Construcción y Tecnología Arquitectónicas de la Escuela Técnica Superior de Arquitectura de la Universidad Politécnica de Madrid
\end{abstract}

\begin{tabular}{|c|c|}
\hline $\begin{array}{l}\text { CRÉDITOS DEL PROYECTO } \\
\text { NOMBRE: }\end{array}$ & Área de Regeneración Urbana del Barrio San Cristóbal de Burgos \\
\hline LOCALIZACIÓN: & Barrio San Cristóbal de Burgos (España) \\
\hline FUNCIÓN: & $\begin{array}{l}\text { A través del proyecto se busca mejorar de las condiciones de habitabilidad de } \\
\text { las viviendas, solucionando las patologías existentes y el comportamiento ener- } \\
\text { gético de estas y regenerar y acondicionar el espacio público a nuevas demandas }\end{array}$ \\
\hline PROMOTOR: & Asociación Plataforma Vecinal ARI Barrio San Cristóbal Burgos \\
\hline AUTOR/ AUTORES & Canal a4 Urbanismo y Arquitectura SLP \\
\hline FECHA (DE PROYECTO Y DE EJECUCIÓN): & $2017-2020$ \\
\hline SUPERFICIE DE LA ACTUACIÓN: & $12,30 \mathrm{Ha}$ \\
\hline COSTE/PRESUPUESTO: & $17.856 .134,27$ \\
\hline NÚMERO DE VIVIENDAS AFECTADAS: & 644 viviendas \\
\hline ESTADO ACTUAL DE LA INTERVENCIÓN: & En ejecución ( $65 \%$ de viviendas rehabilitadas a fecha de 2018$)$. \\
\hline CRÉDITOS DE LAS IMÁGENES: & Rafael Córdoba-Hernández. Noviembre de 2018 \\
\hline
\end{tabular}

${ }^{1}$ Este caso de estudio forma parte de un análisis mayor realizado como resultado del Convenio de Colaboración entre el Ministerio de Fomento y el Instituto Juan de Herrera en 2018 para la incorporación al "Observatorio de la Vulnerabilidad Urbana" del Informe Fórmulas innovadoras de gestión y financiación en actuaciones de regeneración de barrios.

rafael.cordoba@upm.es № ORCID: https://orcid.org/0000-0001-7878-2055; f.carmona.mateos@outlook.es

No ORCID: https://orcid.org/0000-0001-5119-435X; emilia.roman@upm.es No ORCID: https://orcid.org/0000-0001-6746-2793; carmen.sanchezquevara@upm.es No ORCID: https://orcid.org/0000-0002-9612-7633 


\section{Contexto}

El barrio de San Cristóbal, ubicado al noreste de la ciudad de Burgos, está delimitado al norte por el río Vena y al sur por un vial que lo separa físicamente del polígono industrial Gamonal-Vilimar. Su declaración como Área de Rehabilitación Integral (ARI) en 2013 incluía, además de los edificios del propio barrio de San Cristóbal, otros situados al otro lado de la calle del Alcalde Martín Cobos, con unas características tipológicas y urbanísticas similares. El ámbito se compone por tanto de los 26 bloques abiertos de viviendas de 5 plantas del barrio, y de otros 3 situados en el exterior de este: dos bloques en $\mathrm{H}$ de la misma altura, y una torre exenta de 9 . Este programa residencial se ve complementado por tres espacios de carácter dotacional: el centro cultural, un velódromo, y un campo de fútbol donde no se interviene.

Se trata de un barrio de los años 60 , desarrollado al amparo del fuerte crecimiento que sufrió la ciudad como resultado de su dinamización industrial. El proyecto fue uno de los pocos de iniciativa pública en aquel momento, con viviendas de modestas dimensiones (40-76 $\left.\mathrm{m}^{2}\right)$, que contaron en su momento con un precio de venta limitado debido a su carácter social. En 1974, seis años después de la aprobación del proyecto, ya se encontraban terminadas las 500 viviendas que lo conforman en la actualidad. Los 8 portales localizados al otro lado de la calle del Alcalde Martín Cobos son contemporáneos, pero de iniciativa privada.

Con el paso de los años, los vecinos empezaron a denunciar el mal estado de la edificación, la imagen del barrio y, en especial, los cerramientos o fachadas de ladrillo caravista rojo que el tiempo había deteriorado y condenado al envejecimiento. Acompañando estas denuncias se mantuvieron diferentes reuniones y contactos con el Excmo. Ayuntamiento de Burgos y la Junta de Castilla y León, buscando su sensibilización de cara a la presencia urbana del barrio en la ciudad y el reconocimiento del proceso de progresivo deterioro de las infraestructuras y edificios.

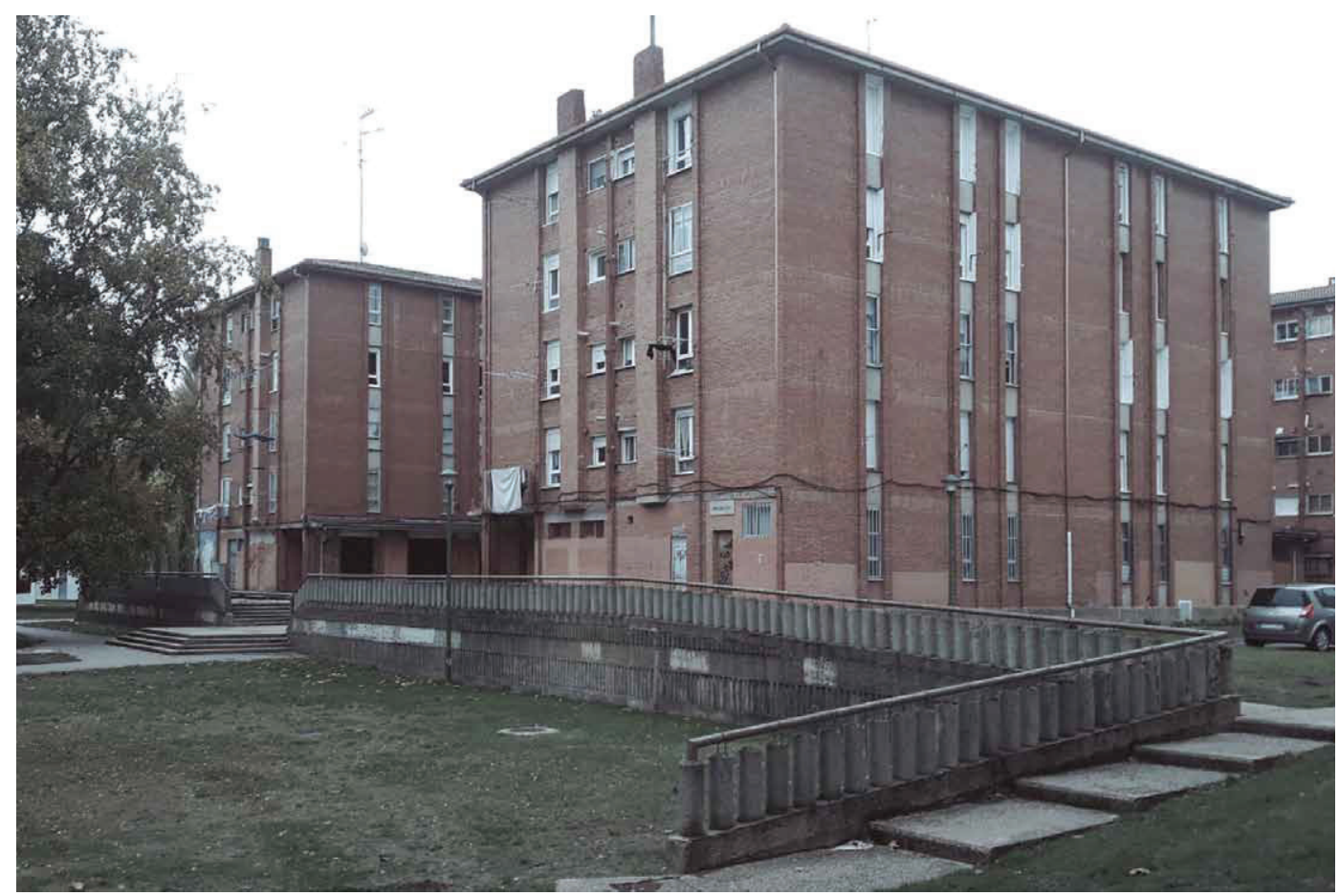

FIG. 1/ Estado preoperacional del barrio.

Fuente: Elaboración propia para Fórmulas innovadoras de Gestión y Financiación en actuaciones de Regeneración de Barrios. 


\section{Estrategias}

Aprovechando la experiencia municipal en el ARI Río Vena, focalizado también en un barrio humilde y de clase obrera construido en 1979 con similares problemas de aislamiento y confort térmico, se planteó la creación de este Área de Rehabilitación Integral, que se terminaría aprobando en 2010. El objetivo del proyecto era aumentar la calidad de vida de los residentes, mejorar sus condiciones de habitabilidad, e impulsar una cierta actividad económica que permitiese un desarrollo integral del barrio. Para ello deberían por un lado solucionarse las patologías existentes y mejorar notablemente el comportamiento energético de las viviendas a través de la envolvente, y por otro buscar la atracción de nuevos comercios, la habilitación y mejora de los locales existentes, así como la regeneración del espacio público para acondicionarlo a las nuevas demandas, colaborar al resurgimiento de la identidad perdida del propio barrio y mejorar la relación de este con la ciudad.

Las actuaciones propuestas se adaptaban a la normativa urbanística vigente en aquel momento: el PGOU de Burgos, aprobado el definitivamente por Órdenes de 18 y 26 de mayo de 1999 del Consejo de Medio Ambiente y Ordenación del Territorio de la Junta de Castilla y León, y su Modificación para adaptarse a la Ley 5/99 de 8 de abril de Urbanismo de Castilla y León, aprobada por Orden de la Consejería de Fomento de la Junta de Castilla y León de 30 de abril del año 2001. También se tenía en consideración la normativa urbanística pendiente de aprobación provisional en aquel momento, el vigente PGOU 2014 (véase FIG. 2), sin necesidad de alterar parámetros sustanciales como la edificabilidad, ocupación o tipologías previas, manteniéndose los criterios compositivos.

Al tratarse de un espacio de intervención con una tipología edificatoria homogénea y con problemas compartidos entre los diferentes bloques, la rehabilitación propuesta puede considerarse sistemática, garantizando la solución en todas y cada una de las viviendas de una forma similar.
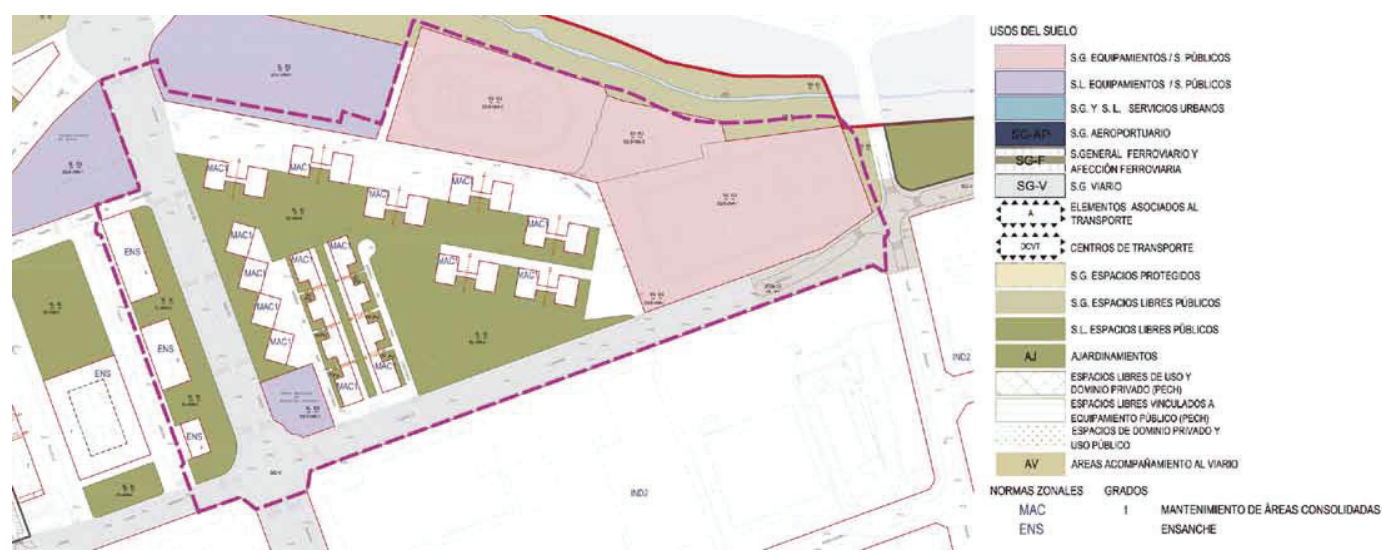

FIG. 2/ Relación del ámbito de intervención con la regulación urbanística vigente del PGOU 2014.

Fuente: Elaboración propia para Fórmulas innovadoras de Gestión y Financiación en actuaciones de Regeneración de Barrios.

Es importante señalar que, en el proyecto, se consideraron de especial importancia las estrategias para aumentar el confort térmico dentro de las viviendas y reducir el consumo energético. No hay que olvidar que Burgos se trata de una ciudad localizada en la zona climática E según el Código Técnico de la Edificación en su Documento Básico Ahorro de Energía, de las más frías de la península. Atendiendo a la composición de la fachada, se estima que se podría estar pasando de una transmitancia térmica (U) de $1,23 \mathrm{~W} / \mathrm{m}^{2} \mathrm{~K}$ a $0,17-0,21 \mathrm{~W} / \mathrm{m}^{2} \mathrm{~K}$, según los datos del Informe Fórmulas innovadoras de gestión y financiación en actuaciones de regeneración de barrios del Ministerio de Fomento.

Las patologías constructivas, junto con la falta de mantenimiento de la urbanización conformaron las líneas de actuación. Las principales patologías estaban producidas especialmente por la ausencia de envolvente térmica en fachadas, cubiertas y soportales. Además, la fachada de ladrillo apoyaba 
directamente sobre los cantos de forjado a sardinel, provocando fisuras en las fachadas apreciables desde el exterior. Durante los años previos a la intervención, los propios vecinos intentaron resolver estos problemas mediante tabiquerías interiores o pinturas hidrófugas variopintas, pero los puentes térmicos horizontales eran mayores que el propio forjado y estas soluciones no funcionaron. En los estudios anteriores a la intervención se detectó como los distintos puentes térmicos eran los causantes de condensaciones de todo tipo en cámaras y paños interiores, así como filtraciones que atravesaban las distintas fachadas y encuentros con carpinterías de ventanas. También se revelaron fuertes problemas de capilaridad desde cimentación en las viviendas en planta baja, ya que el zócalo de hormigón nacía directamente desde la propia zapata corrida.

Ante el deterioro de las fachadas de ladrillo caravista derivado de los efectos de heladicidad y desprendimiento de sardineles, se planteó la eliminación de las chimeneas adosadas en desuso y con riesgo de desprendimiento, y se propuso realizar una nueva envolvente térmica de fachada ventilada cerámica con aislamiento incorporado entre subestructura de aluminio, que garantizase la estanqueidad ante filtraciones. Por su parte, para solventar las patologías de estanqueidad a lluvia en los recercados de ventanas, debido a la inexistencia de cámara de aire en todo su perímetro, se planteó una solución mediante mochetas de composite con aislamiento incorporado, compatible con la nueva fachada ventilada. Ante esta misma falta de estanqueidad, en cubiertas de soportales y edificios, se optó por una nueva impermeabilización y la recogida de aguas hasta unos renovados colectores.

Esta nueva envolvente térmica, transpirable y estanca a la lluvia, busca resolver de forma simultánea la eficiencia energética y la sostenibilidad mediante la dotación de aislamiento térmico continuo al conjunto de las viviendas, aumentando con ello su habitabilidad. El aislamiento, por su parte, es un extruido ignífugo de $6 \mathrm{~cm}$ de espesor. Con ambos elementos se busca reducir hasta un $45 \%$ de la energía consumida en la actualidad.

Otro de los problemas considerados por el proyecto es la accesibilidad física, que presentaba deficiencias tanto en los edificios como en la urbanización. Esta última exhibía barreras arquitectónicas en la totalidad de los usos asociados a los espacios de ocio, ya fueran públicos o privados. En la edificación, la falta de ascensor en el proyecto original había ocasionado que algunos vecinos realizaran el esfuerzo de instalarlo, pero no todos los edificios contaban con ellos. Además, tampoco se construyeron

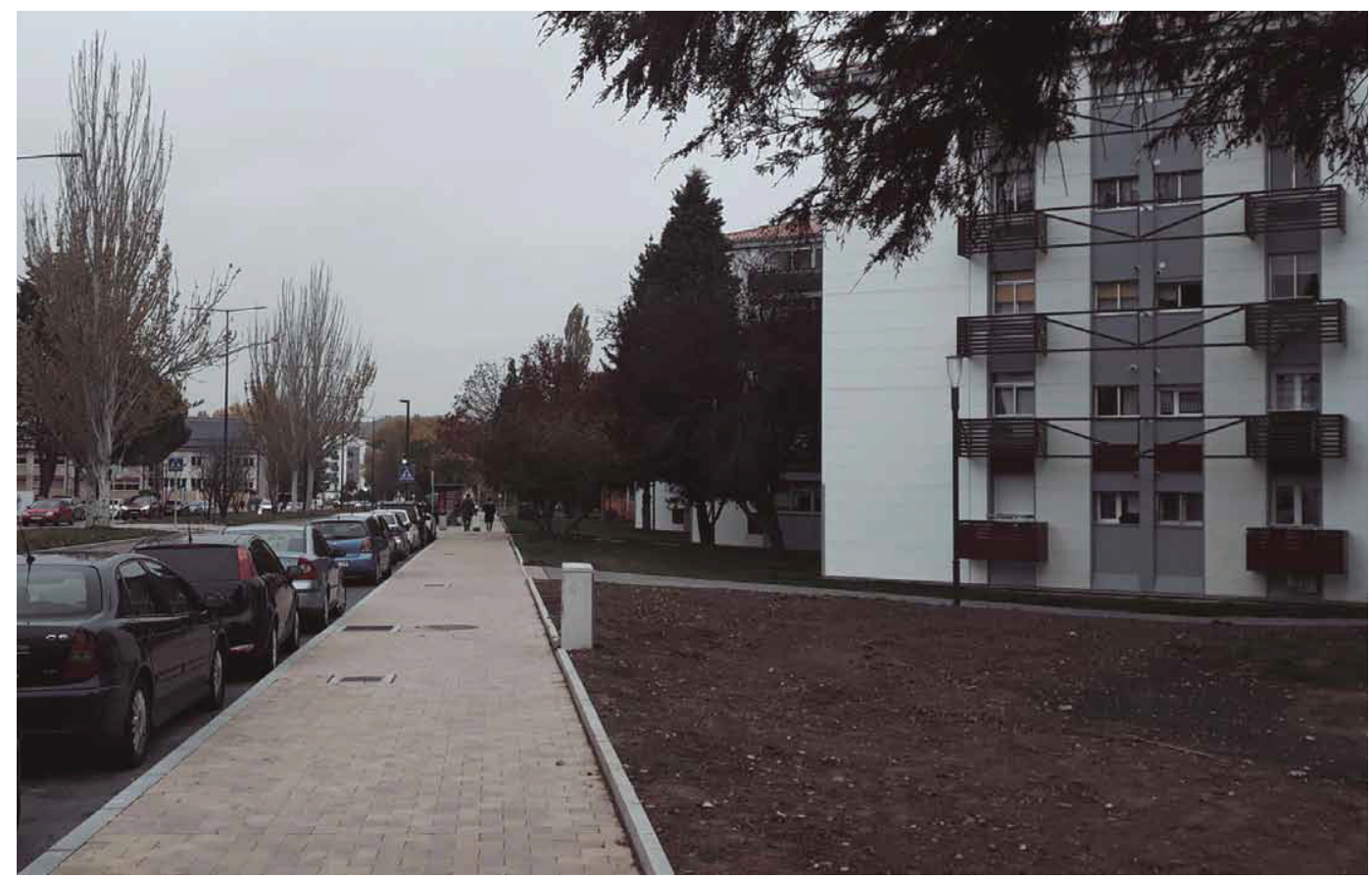

FIG. 3/ Relación del ámbito de intervención con la regulación urbanística vigente del PGOU 2014.

Fuente: Elaboración propia para Fórmulas innovadoras de Gestión y Financiación en actuaciones de Regeneración de Barrios. 
originariamente rampas de acceso en los bloques. Por ello, el ARI valora la renovación e instalación de ascensores hasta en 15 portales y la supresión de los problemas de accesibilidad desde cota cero a través de la construcción de rampas de acceso. Para la incorporación del ascensor, y dada la formalización del acceso original y la distribución de las viviendas en los diferentes rellanos, se hizo necesaria la adaptación del ojo de escalera.

Por último, el estado de conservación de las zonas verdes difería de unos espacios a otros, presentando por lo general una mejor conservación en las ajardinadas que en las silvestres, y en concreto las más alejadas de la edificación podrían catalogarse en estado de abandono. Los caminos pavimentados, estrechos y con numerosas barreras arquitectónicas, se encontraban bastante deteriorados, con elementos rotos o hundidos. El mobiliario urbano se consideró insuficiente y en mal estado. A todo esto, se le sumaba que, con el paso de los años, el espacio destinado al aparcamiento se había ido quedando pequeño, y los propietarios habían dejado de aparcar en línea, pasando a hacerlo en batería, con la reducción del espacio que esto supone para la circulación. Además, la red de alumbrado exterior no cumplía los estándares actuales de eficiencia energética.

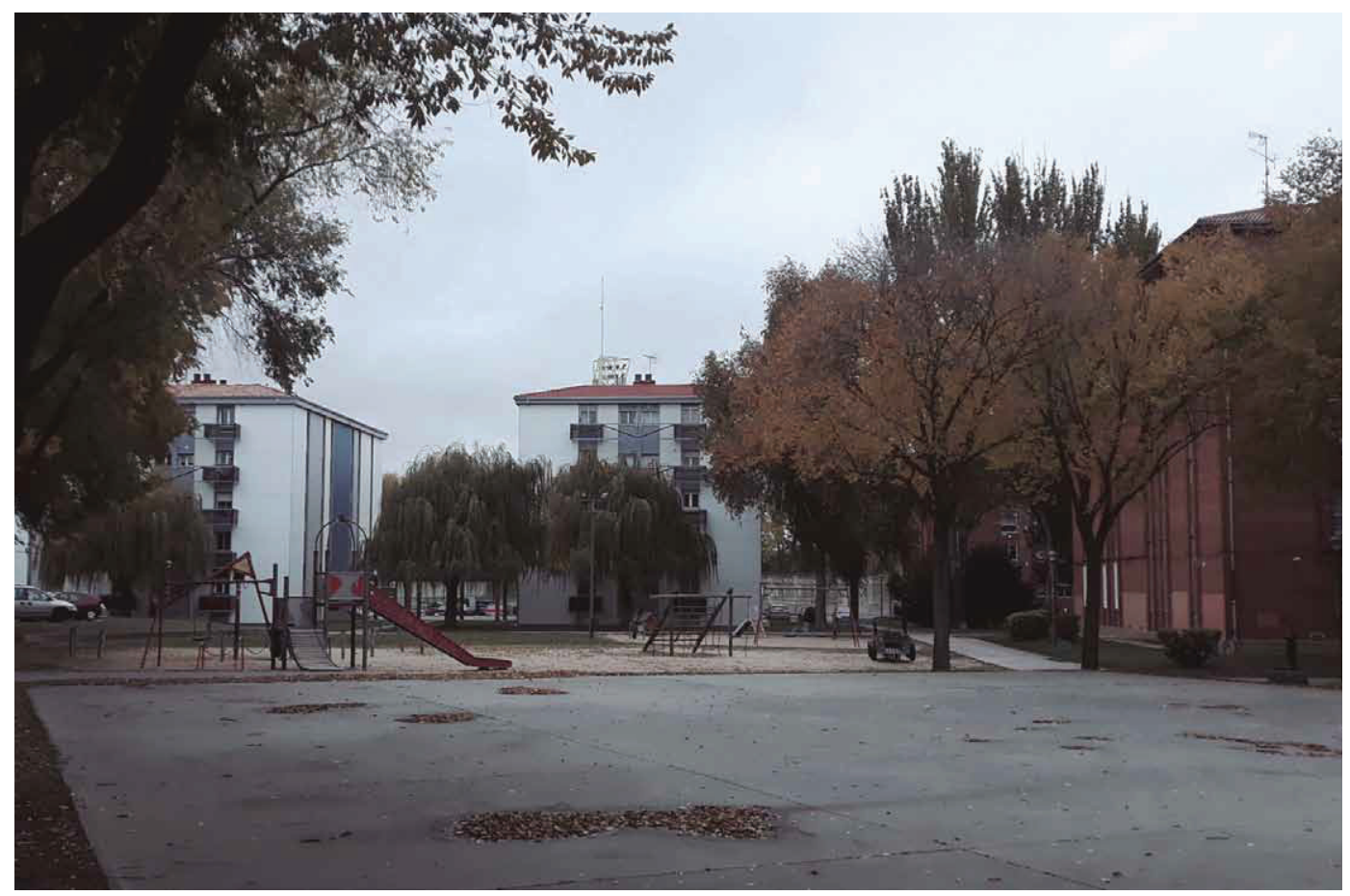

FIG. 4/ Imagen de los espacios libres del barrio de San Cristóbal..

Fuente: Elaboración propia para Fórmulas innovadoras de Gestión y Financiación en actuaciones de Regeneración de Barrios.

\section{Financiación y Gestión}

La fórmula prevista de financiación del proyecto es la recogida en el RD 233/2013 de 5 de abril, por el que se regula el Plan Estatal de fomento del alquiler de viviendas, la rehabilitación edificatoria, $y$ la regeneración y renovación urbanas, 2013-2016. Este modelo contaba con subvenciones para la rehabilitación de viviendas y edificios, y superación de situaciones de infravivienda, por un importe máximo del $40 \%$ del total, con una cuantía media máxima por vivienda rehabilitada de $5.000 €$; una serie de subvenciones destinadas a obras de urbanización y reurbanización en el espacio público, por un importe máximo del $20 \%$ del total; y subvenciones para la financiación parcial del coste de los equipos de información y gestión, cuyo importe máximo no podrá exceder del $50 \%$ de este, ni del $5 \%$ del presupuesto protegido total del ARI. 
La estrategia de colaboración económica entre las administraciones implicadas (locales, autonómicas, estatales y vecinales) quedó respaldada por las aportaciones económicas previas al inicio de las obras por parte de las familias. Además, para prevenir la especulación con la vivienda, se obligaba a los vecinos a conservar la misma durante al menos 5 años, estableciéndose que en caso contrario se debería devolver el total de las subvenciones.

La gestión se caracteriza por la participación vecinal dentro y fuera del barrio. Los vecinos se integraron bajo la denominación de Asociación "Plataforma Vecinal ARI Barrio San Cristóbal Burgos" y junto con el ayuntamiento burgalés constituyeron la "Asociación para la Regeneración Urbana ARU San Cristóbal Burgos" como una entidad colaboradora en la gestión de las ayudas en mayo de 2015.

La importante participación vecinal permitió actuar bajo un amplio consenso entre todos los agentes en las actuaciones propuestas, pero a su vez requirió un proceso previo y complejo para proporcionar información particularizada a todos y cada uno de los vecinos del barrio, sus asociaciones y representantes, en un proceso que se alargó durante 6 años. En la actualidad el papel de los vecinos sigue siendo muy relevante para la toma de decisiones.

\section{Resultados}

La evaluación de las políticas analizadas en el caso de San Cristóbal queda marcada por el estado de ejecución del mismo, que, aunque bastante avanzado, no está concluido, habiéndose ejecutado un $64,71 \%$ de los portales y $65,22 \%$ de las viviendas, y quedando pendiente especialmente la intervención sobre el espacio público, ya que se ha priorizado las actuaciones sobre las viviendas. Así, las zonas de espacios comunes no están tratadas y todavía es posible ver cables del tendido telefónico al aire si se visita la zona.

Para la evaluación de los diferentes casos seleccionados, se utiliza la metodología desarrollada por el Departamento de Urbanística y Ordenación del Territorio de la Universidad Politécnica de Madrid en la Estrategia para el diseño y la evaluación de planes y programas de regeneración urbana integrada en el marco del Plan Nacional de I+D+i 2013-2015. Dicha metodología, desarrolla una herramienta de evaluación para los planes de Rehabilitación Urbana Integrada que permite analizar una significativa variedad de aspectos previos y posteriores a la actuación enmarcados en cuatro grandes grupos: Marco Urbano y Territorial; Diseño Urbano y Medio Ambiente Local; Edificación, y Socioeconómico.

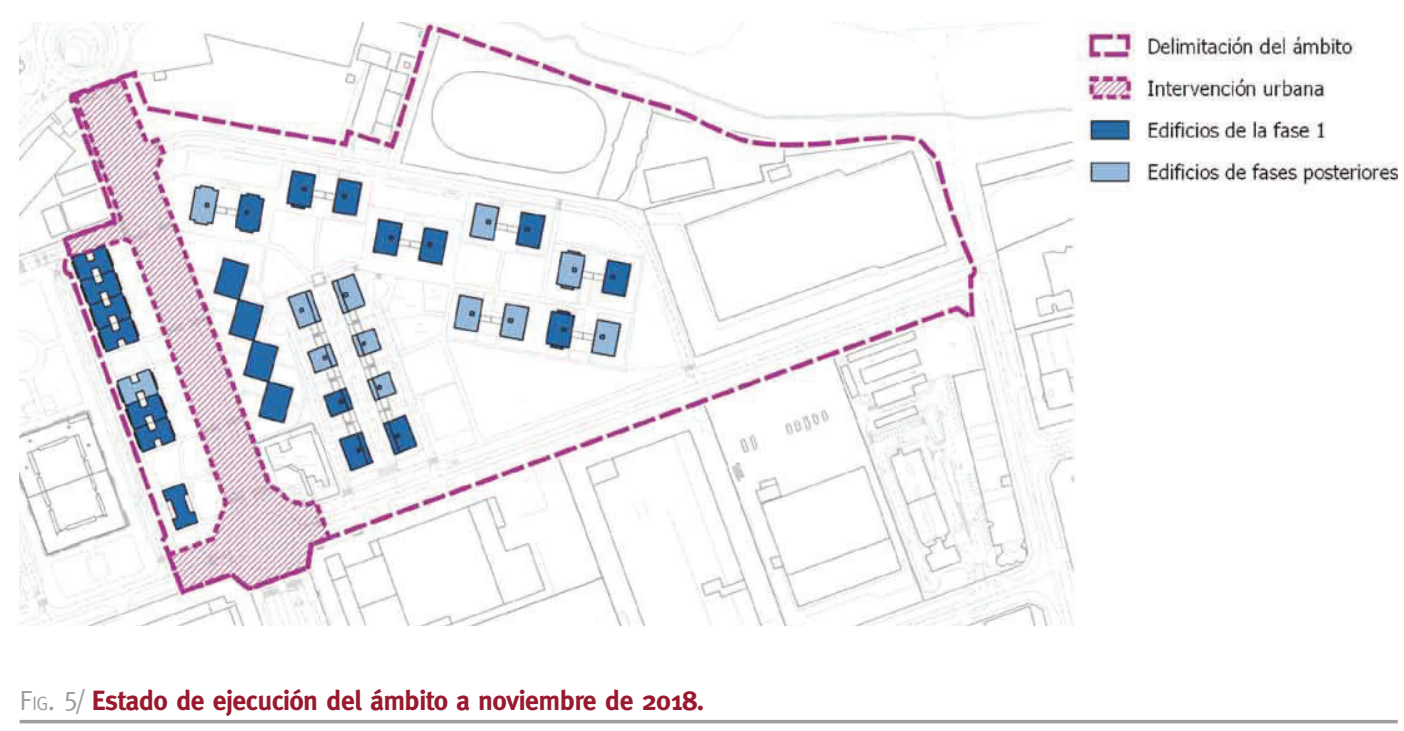

Fuente: Elaboración propia para Fórmulas innovadoras de Gestión y Financiación en actuaciones de Regeneración de Barrios. 
De ellos, tan sólo en las categorías de edificación y socioeconómicas se alcanza la satisfacción con respecto al modelo previsto según los evaluadores. En el resto, al no ser contempladas o permanecer inconclusas las obras, la valoración es mejorable o insuficiente. En los campos considerados satisfactorios, se valora el buen funcionamiento e implicación en el proceso de la Asociación para la Regeneración Urbana ARU San Cristóbal, así como la marcha de las propias obras en la edificación, que parecen estar satisfaciendo a los propios vecinos tanto por su ejecución como por los resultados de mejora de habitabilidad.

Dentro del área socioeconómica sólo se trabajan temas de Foros de participación y relaciones entre actores sociales dentro del ámbito, a través de la propia Asociación de la que forman parte representantes de los vecinos del barrio.

Por su parte, las principales mejoras encaminadas a la mejora del Diseño Urbano y Medio Ambiente Local están pendientes de ejecución. En la primera fase llevada a cabo tan sólo se reurbanizó la calle Alcalde Martín Cobos y dispuso un carril bici a lo largo de esta. El resto de las actuaciones se realizarán tras la rehabilitación de todos los bloques residenciales. Estas irán encaminadas, entre otros aspectos, a aumentar el número de plazas de aparcamiento en el ámbito.

Destacan las acciones sobre lo que podríamos entender como Patrimonio e identidad. Desde el inicio estaba considerada la posibilidad de dotar al ámbito de un carácter e identidad propia, que se promueve a través del acabado de los edificios y la utilización de unos colores concretos en las bandas coloridas del mismo, claramente diferenciada de la homogeneidad que tenía el ámbito con el anterior acabado en ladrillo que no terminaba de encajar con la imagen que querían los vecinos para el barrio. Además, cada uno de los edificios rehabilitados adquiere la denominación de uno de los hitos del Camino de Santiago, pese a mantener su tradicional numeración.

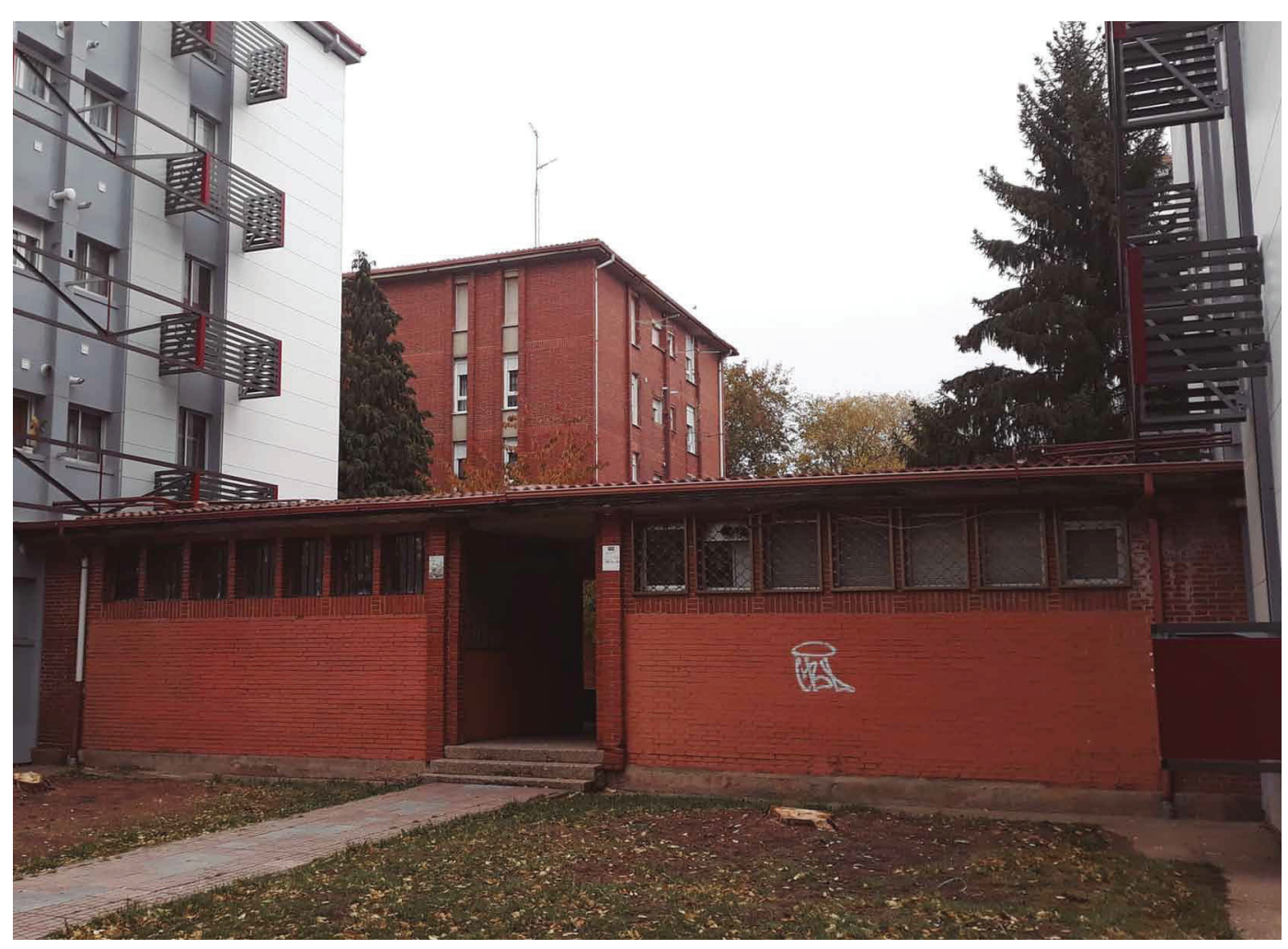

FIG. 6/ Estado intervención 2018 donde se aprecia identidad nueva del barrio frente a previa.

Fuente: Elaboración propia para Fórmulas innovadoras de Gestión y Financiación en actuaciones de Regeneración de Barrios. 


\section{Bibliografía}

Canal A4 Urbanismo y Arquitectura SLP (2013): Proyecto ARI Barrio San Cristóbal, Burgos.

HeRnÁndez AJA, Agustín \& al. (2016): Recuperando la ciudad. Estrategia para el diseño y la evaluación de planes programas de regeneración urbana integrada. Instituto Juan de Herrera, Madrid. ISBN 978-84-9728-518-6. Versión accesible en: http://oa.upm.es/43837/

— \& al. (2018): Fórmulas innovadoras de gestión y financiación en actuaciones de regeneración de barrios. Monografía (Informe Técnico). Ministerio de Fomento. Versión accesible en:

https://www.fomento.es/arquitectura-vivienda-y-suelo/urbanismo-y-politica-de-suelo/observatorio-de-la-vulnerabilidad-urbana/informe-formulas-innovadoras-gestion-financiacion-actuaciones-regeneracion-barrios

MinISTERIO DE FOMENTO (2013): Real Decreto 233/2013, de 5 de abril, por el que se regula el Plan Estatal de fomento del alquiler de viviendas, la rehabilitación edificatoria, y la regeneración y renovación urbanas, 2013-2016. Publicado en BOE $n^{\circ} 86$ de 10 de abril de 2013. 